\title{
Categorical Ways of Acting
}

Remarks on C. I. Lewis' Amendment of Kantian a priori

Rosa M. Calcaterra

\section{(2) OpenEdition \\ Journals}

Electronic version

URL: http://journals.openedition.org/ejpap/368

DOI: $10.4000 /$ ejpap.368

ISSN: 2036-4091

Publisher

Associazione Pragma

\section{Electronic reference}

Rosa M. Calcaterra, « Categorical Ways of Acting », European Journal of Pragmatism and American Philosophy [Online], VII-1 | 2015, Online since 07 July 2015, connection on 25 April 2019. URL : http:// journals.openedition.org/ejpap/368; DOI : 10.4000/ejpap.368

This text was automatically generated on 25 April 2019.

\section{(c) $($ ) $\odot$ (8)}

Author retains copyright and grants the European Journal of Pragmatism and American Philosophy right of first publication with the work simultaneously licensed under a Creative Commons AttributionNonCommercial-NoDerivatives 4.0 International License. 


\title{
Categorical Ways of Acting
}

\author{
Remarks on C. I. Lewis' Amendment of Kantian a priori
}

\author{
Rosa M. Calcaterra
}

\section{An Anomalous Pragmatism?}

1 I intend to propose the possibility of considering the "conceptual pragmatism" of C. I. Lewis as a useful epistemological orientation to discuss the relationship between the social and the individual, in particular as it is set out in Bourdieu's sociology of practice. From a pragmatist point of view, the centrality Bourdieu assigns to the concepts of habit and of culture as a 'second nature' seems important, amounting to a sort of naturalism. Thus the specific point for which I think Lewis' epistemology could be taken into account is the connection between habitus and 'social schematism,' which Bourdieu develops in the wake of Kant while the American philosopher considers concepts and ideas as logical schemata constructed by the human mind in order to face and deal with experiential data.

2 I use the term 'experiential data' in a broad sense, namely according to the significance generally given by classical pragmatists to the term 'experience' which is, in fact, quite different from that customarily implied in traditional empiricism. To be sure, the pragmatist usage of this term as a logical/semantic entity which covers both mental and sensorial space marks an important difference between pragmatism and traditional empiricism that normally restricts the notion of experience to sense impressions. Most importantly, pragmatist philosophers' positive reaction to Darwinian biology caused them to emphasize the dynamic feature of any kind of experience, namely of the interactive, constructive, and social nature of the relationship between the subject and the object of experience. ${ }^{1}$ These features are all well embedded in Lewis's effort to combine pragmatism and Kantianism. Accordingly, he is known as an exponent of the 20th century neo-Kantian trend, in particular as a representative of the contemporary 'naturalistic' turn in appraisals of the Kantian a priori that Bourdieu himself seems to support. 


\section{A Dynamic Approach to the a priori Issue}

3 The wording "categorical ways of acting" used in the title of this article was coined by Josiah Royce, a follower of Hegelian idealism, who was highly praised by Clarence Irving Lewis during his university studies at Harvard. Subsequently, Lewis openly criticized the neo-Hegelian solutions offered by Royce to some pivotal epistemological questions. Nevertheless, Lewis decided to borrow Royce's diction "categorical ways of acting" to present his own conception of the a priori, which constitutes the distinctive aspect of his pragmatist theory of knowledge. ${ }^{2}$

4 It is not easy to assign a univocal label to the work of Lewis. For example, one might ask: was he a foundationalist or a coherentist, a realist or an idealist, an empiricist or a logicist? A new and very strange (or perhaps extravagant) term has been coined by Susan Haack to define his position "proto-foundherentist," namely an attempt to amalgamate foundationalism and coherentism, which in fact are normally considered to be deeply discordant. ${ }^{3}$ Nor does it seem easy to localize Lewis's epistemology in one of the two great currents of the philosophical tradition, empiricism and rationalism. Rather, according to my interpretative hypothesis, the main reason why his work is interesting is precisely for its commitment to overcome the classical dichotomy empirical/rational, providing arguments that support the pragmatist project of establishing the criterion of action and the social dimension of knowledge as antidotes to the sceptical implications of empiricism, on the one hand, and to the rationalist pretensions of certainty or absolute epistemic grounds, on the other. In any event, Lewis does not hesitate to count himself among the pragmatists, declaring more than once his debt to the thought of James and Peirce and, above all, characterizing the theory of knowledge presented in his best known work, Mind and the World Order, 'conceptual pragmatism.' Yet Lewis' is an anomalous pragmatism with regard to the important positions of both the 'founding fathers' of this trend of thought, and of the neo-pragmatist philosophers.

5 In particular, Lewis' epistemology certainly draws upon the fundamental factor of the work of Peirce and James, namely, their insistence upon the epistemic value of action. Nevertheless, Lewis' perspective diverges from that of Peirce and James regarding an aspect that is equally essential, i.e. the Kantian problem of the a priori conditions of experience. As we know, Peirce and James maintained a quite negative attitude towards the very possibility of the a priori as governing structural, universal, and necessary forms of the mind. ${ }^{5}$ Lewis agreed with such an attitude but, unlike Peirce and James, he attempted to argue that knowing activities are based upon conceptual frameworks established by thought independently of experience and consisting of sets of analytic truths that, however, are susceptible to change.

6 The a priori issue was also a key problem for logical positivism. Together with Charles Morris and John Dewey, Lewis was one of the most assiduous American interlocutors of the logical empiricists, with whom he initially found considerable harmony In particular, he agreed with the logical empiricists on a crucial point, that is, the negation of synthetic a priori judgements. However, Lewis' philosophy of language diverged significantly with respect to a number of neo-positivist claims, first of all the assertion of a possible linguistic version of the a priori. These divergences would be useful when clarifying Lewis's specific position among promoters of the so called 'liberalization' of logical empiricism, and in particular his relationship with Quine, who attended Lewis' doctoral 
courses at Harvard. At the same time, it is important to consider that, in spite of some interesting affinities between the two philosophers, Lewis was surely one of the targets of Quine's famous attack on the analytic/synthetic dichotomy.

7 The works by Lewis in the field of mathematical logic are usually considered the least important part of his philosophical legacy but, in fact, they are the basis of his epistemological stance and, more specifically, of the pragmatic version of the a priori he advanced in later years. To summarize as much as possible, one can say that the pragmatic version of the a priori is linked to the pivotal assertion of Lewis' mathematical logic, namely that logical implication consists of an intensional relationship and is not an extensional aspect of inference as was commonly considered. More precisely, Lewis aimed at recovering the semantic level of logic and for this reason he rejected the criterion of 'material implication' presented as a paradigm of the deductive inference in Russell's and Whitehead's Principia Mathematica. ${ }^{6}$ According to Lewis, such a criterion does not take into account the fact that our usual way of making a deducing consists of the construction of a relationship based upon the meaning of the proposition's premises and its consequences, and not only upon their formal truth or falsity value, as Russell's principle in fact indicated. Indeed, this criticism is an essential aspect of Lewis's conception of the a priori since it is based upon the notion of necessary truth and the correlated distinction between analytic truths and synthetic truths, which Lewis proposed in his 1923 essay, A Pragmatic Conception of the A Priori. In a nutshell, this essay foregrounds a dynamic approach to the transcendental issue that takes advantage of current developments in physical science and mathematics. Here is an illuminating passage:

The conception of the a priori points to two problems which are perennial in philosophy: the part played in knowledge by the mind itself, and the possibility of "necessary truth" or of knowledge "independent of experience." But traditional conceptions of the a priori have proved untenable. [...] The difficulties of the [traditional] conception are due, I believe, to two mistakes: whatever is a priori is necessary, but we have misconstrued the relation of necessary truth to mind; and the a priori is independent of experience, but in so taking it, we have misunderstood its relation to empirical fact. What is a priori is necessary truth not because it compels the mind's acceptance, but precisely because it does not. It is given experience, brute fact, the a posteriori element in knowledge which the mind must accept willy-nilly. The a priori represents an attitude in some sense taken freely, a stipulation of the mind itself, and a stipulation which might be made in some other way if it suited our bent or need. (Lewis 1923: 231)

In other words, the a priori are instruments created by the human mind to organize the events of experience or the criteria that we decide to use to define and classify them, choosing from a series of "conceivable alternatives" that in any case do not alter the reality of the given. In fact, according to Lewis, the a priori does not anticipate the given but simply our attitude towards it, an attitude the validity of which is measured pragmatically, that is, in relation to the normative function that the a priori propositions perform within reasoning processes, as well as in relation to their ability to deal with the complexity of empirical data. For this reason, we can certainly share the traditional idea that the a priori is typically represented by the laws of logic considered as analytic truths. But we should also be aware that there is, in principle, an infinity of logical systems, that is to say, it is possible to construct alternative systems, each one based upon different formal criteria, and this requires searching for the confirmation of their validity beyond the field of logic. Hence, for Lewis, the ultimate criteria of logical laws are pragmatic and the necessity of the a priori principles require "neither universal agreement nor complete 
historical continuity." In fact, "Conceptions, as those of logic, which are least likely to be affected by the opening of new ranges of experience, represent the most stable of our categories; but none of them is beyond the possibility of alteration":

The dividing line between the a priori and the a posteriori is that between the principles and the definitive concepts which can be maintained in the face of all experience and those genuinely empirical generalizations which might be proven flatly false. The thought which both rationalism and empiricism have missed is that there are principles, representing the initiative of mind, which impose upon experience no limitations whatever, but that such conceptions are still subject to alteration on pragmatic grounds when the expanding boundaries of experience reveal their infelicity as intellectual instruments. (Lewis 1923: 239-40) ${ }^{7}$

The dynamic nature of the mind is also translated, therefore, into the realm of concepts, of principles, of categories, of definitions - all terms that Lewis uses interchangeably and characterizes as "distinctly social products." They are rooted in the basic shared abilities and needs of human beings, in language, in the exchange of ideas and experiences, finally "in the coincidence of human purposes and the exigencies of human cooperation." Mind and the World Order confirms this perspective by offering a set of argumentations which aim at clarifying the distinction between empirical data and the a priori dimension. Some ambiguities on the matter appear unresolved, however the essential point of previous discussion remains:

The a priori is not a material truth, delimiting or delineating the content of experience as such, but is definitive or analytic in its nature. (MWO: 231)

Lewis repeats that, whilst a priori propositions are products of the mind and are thus susceptible to change, they are not arbitrary. Rather, they respond to criteria of selfconsistency ${ }^{8}$ which also reflect upon the rules of their application, as he indicates in this passage:

The paradigm of the a priori in general is the definition. It has always been clear that the simplest and most obvious case of truth which can be known in advance of experience is the explicative proposition and those consequences of definition which can be derived by purely logical analysis. These are necessarily true, true under all possible circumstances, because definition is legislative. Not only is the meaning assigned to words more or less a matter of choice [...] but the manner in which the precise classifications which definition embodies shall be affected, is something not dictated by experience. If experience were other than it is, the definition and its corresponding classification might be inconvenient, useless, or fantastic, but it could not be false. Mind makes classifications and determines meanings; in so doing, it creates that truth without which there could be no other truth. (MWO: 239-40)

\section{Epistemological Triangulation: Schemas, Actions, and Reality}

11 The assertion of the 'determining' power that classifications or a priori concepts exert upon the meanings we assign to experiences suggests a quite solid relativism or even an idealist perspective, which actually seems to be confirmed by Lewis's claims concerning a strict connection between conceptual schemes and the definitions of what is real or unreal. Indeed, there are a number of passages in his work that consider not only meanings and empirical or practical truths, as suggested in the above quotation, but also definitions of reality as dependent upon the concepts we use. "Decisions on reality and 
unreality are themselves interpretations involving principles of the same order as scientific law," he writes, and "whatever is denominated 'real' must be something discriminated in the experience by criteria which are antecedently determined" (MWO: 261). However, 'conceptual pragmatism' also emphasizes the decisive role of practical experience in determining what can be taken for 'real' or 'unreal' in a quite strong or metaphysical sense:

Our categories are guides to action. Those attitudes which survive the test of practice will reflect not only the nature of the active creature but the general character of the experience he confronts. (MWO: 21)

To sum up these two apparently different argumentations, what we define as real implies or, more precisely, implements our conceptual schemes but these latter are, in turn, normative categories whose commitments must be interrelated with genuine realities, since otherwise they would not work at all as classifications/definitions that - according to Lewis - aim at meeting our needs and purposes. ${ }^{9}$

It would be worth confronting such a perspective with Wittgenstein's conception of the normative system that supports our linguistic and epistemic practices, that complex of shared certainties forming the 'common sense' which Wittgenstein represented with metaphors of the 'river-bed' and 'scaffolding' to describe the grounding function they perform with respect to events that affect our knowledge. ${ }^{10}$ In particular, the pages dedicated to this issue suggest a notion of reality that appears in part similar to that of Lewis in so far as they share an epistemological attitude aimed at overcoming the traditional counter-position of realism and anti-realism. More specifically, in his wellknown polemic against Moore's conception of common sense, Wittgenstein maintained (similarly to Lewis's statements concerning the empirical independence of categorical laws) that the certainties of which common sense proves to be composed do not have true empirical justification. They do not, therefore, constitute knowledge but rather, have a function similar to that of the rules of a game. Obviously, this is a very important function. Common sense beliefs are "the inherited background against which I distinguish between true and false" (OC: § 94), and this set of beliefs is similar to "a kind of mythology" shaped by "propositions describing this world picture," and which are adhered to irrespective of the question of their empirical correctness (OC: $\S 95$ ). This is like saying that what counts is not the correspondence of such images to some 'true' reality, but rather the fact itself that they exist, and this, in turn, means neither more nor less than that they function in the practice of language.

According to Wittgenstein, just as a person normally learns the basic rules of living in a particular natural and social environment by putting them into practice, the images of the world that function as a backdrop to our language games are not necessarily the subject of explicit teaching. They can be learned "purely practically" (OC: § 95). They form "a system" which "belongs to the essence of what we call an argument," that is: "The system is not so much the point of departure, as the element in which arguments have their life" (OC: § 105). In what manner or on the basis of what 'principle' the beliefs of common sense and their normative force take form is a question that Wittgenstein takes out a possible definition in the traditional sense, and this is in fact a strong obstacle to any attempt to classify him among the realists or the anti-realists. Indeed, this very possibility depends, more or less implicitly, upon an assumption typical of traditional foundationalism, that is to say, on the search for an absolute primum of our cognitive abilities, whether of a logical-rational nature or of an empirical-sensory nature. 

shown to be impracticable, and my interpretative hypothesis is that Lewis and the other classical pragmatists attempted to contribute to such a philosophical attitude. ${ }^{11}$ Of course, Wittgenstein's epistemology is very ambiguous and, in particular, it must be acknowledged that his wording is often extraneous to Wittgenstein's philosophical vocabulary. Most importantly, it is not immediately evident that Lewis's conception of categorical laws matches the set of certainties underlying common sense discussed by Wittgenstein, and it is questionable that the latter would fully share Lewis's idea of the 'creative' capacity of human thought. However, focusing upon the differences between them, in addition to the analogies of their theoretical perspectives, could be a fruitful strategy to explore the intertwining of conceptual schemas, actions, and reality, which the American philosopher continues to do in his own version of Pragmatism. In any event, such an intertwining should be accounted as a theoretical framework for reshaping the issue of the relationship between sociality and individuality that is clearly pivotal for both social sciences and philosophical research. A collaborative attitude on the matter is actually important for implementing and improving Lewis's commitment to observe, describe, and interpret the effective functioning of the philosophical network constituted by conceptual schemas, actions, and reality. In fact, his perspective includes an option in favor of the externalist methodology in philosophy that, in principle, tallies with the methodological attitude that characterizes contemporary social sciences.

In any event, it is by virtue of the epistemological triangulation of conceptual schemas, actions, and reality that Wittgenstein constantly re-asserts the pragmatist idea of the critical function of philosophy. Philosophy is the "study of the a priori" and its method is reflexive. It must study the means that we already possess for approaching the facts of experience and constructing our beliefs. It must investigate the concepts that are shared by scientific and practical-moral knowledge in order to make them explicit and evaluate their function within our operations of ordering givenness. Regarding metaphysics, Lewis considers its principles - 'physical,' 'psychical,' 'matter,' 'spirit' - as categories by means of which we refer to different aspects of reality. The task of metaphysics is to acknowledge them correctly, namely, to state the 'rules' by which we distinguish the real from the unreal. Thus metaphysical research does not diverge from a conceptual pragmatism that properly consists in studying the 'interpretative rules' we deliberately adopt to understand reality and its giveness. But the very notion of 'givenness' leads us to wonder about the second term of the a priori/a posteriori conceptual couple. In other words, what is Lewis's conception of the a posteriori empirical level? Some problems arise at this point.

\section{Giveness and Meaning}

The notion of the sensory given is constitutive in Lewis's epistemology and, above all, there are many passages in which he supports the priority of the given as an object of immediate sensory perception. In particular, there is a rather indiscriminate use of the expression 'the given,' which has inevitably been the cause of many different attacks on Lewis. ${ }^{12}$ As a matter of fact, one often has the impression that he supported an empirical translation of Cartesian foundationalism in addition to the isolationist conception of empirical knowledge against which James and Peirce had addressed very substantial arguments. Nevertheless, Lewis's familiarity with the thought of James and Peirce is 
anything but secondary to the construction of his epistemology. Moreover, the ambiguities in his use of the terms 'given' and 'givenness' should assume the triadic structure of his theory of knowledge, namely the assertion that cognitive processes include three factors tightly interconnected that can be told apart only for the purpose of analysis: the given, the concept, and the interpretation of the 'given' by means of the concept. According to this view, the sensory given cannot ever constitute knowledge by itself, being simply a starting point for cognitive processes, for the construction of propositions about objective reality, which cannot be reduced to any possible content of sensory experience.

It is possible to already discern in A Pragmatic Conception of the A Priori and in the 1926 article The Pragmatic Element of Knowledge, that the definition of the three factors of knowledge - the given, the concept, and the interpretation - is an attempt to make fruitful use of the lesson of Peirce, specifically of his triadic theory of meaning and the notion of Generals. In particular, the 1926 essay assigns importance to the theme of interpretation and its connection to the pragmatist idea that knowledge has to do with the problems raised by our needs and interests. These issues are actually set out by Lewis as the elements that distinguish Pragmatism from Idealism, as well as from 'mystics' and the supporters of 'pure perception' à la Bergson. Lewis writes:

Pragmatism is distinguished by the fact that it advances the act of interpretation, with its practical consequences, to first place. [...] These are, then, the bare fundamentals of the pragmatist position concerning knowledge: that knowledge is an interpretation, instigated by need or interest, and tested by its consequences in action, which individual minds put upon something confronting them or given to them. On any theory, it is to be expected that minds will largely coincide and that agreement, for various obvious reasons, will be the rule. But the extent and manner of such coincidence is, for pragmatism, something to be noted in particular cases, not simply the result of universal human reason. (Lewis 1926: 240-1)

The link between the activity of interpretation and the pragmatic aspect of knowledge prompts us to put aside the idea of 'pure perception' of the data of experience. As Lewis explains in Mind and the World Order, if such an expression means the apprehension of a pure givenness, it is definitely a philosophical abstraction. Otherwise we would have to admit something like pure aesthesis, for which there would exist only data isolated in one unique experience or in a unique state of consciousness that, according to Lewis, are truly untenable. In any event, such data are not essential on a cognitive level, precisely because they would be incommunicable. In other words, the given constitutes an essential point of reference for language and concepts. However, it exceeds their boundaries just because it promotes them:

In our knowledge of the external world, concepts represent what thought itself brings to an experience. The other element is 'the given.' It represents that part or aspect which is not affected by thought, the "buzzing, blooming confusion," as James called it, on which the infant first opens his eyes.

It is difficult to make a clean separation of what is given in experience from all admixture of conceptual thinking. The given is something less than perception, since perception already involves analysis and relation in cognition. One cannot express the given in language, because language implies concepts, and because the given is just that element which cannot be conveyed from one mind to another, as the qualia of colour can never be conveyed to the man born blind. But one can, so to speak, point to the given. (Lewis 1926: 248-9) of knowledge precisely because, for Lewis, this aspect coincides with immediacy and the 
mere immediate given of experience "is never what we mean by knowledge" (Lewis 1926: 249). This is actually the outline of the basic criteria of a behaviourist theory of meaning, whose pivotal point is the concept of connotation rather than that of reference. ${ }^{13}$

Overall, the remarks on the question of meaning, to which An Analysis of Knowledge and Valuation is mostly dedicated, constitute a development of preceding Lewis studies of the intensional aspect of logic. In this respect, the distinction between "terminating" and "non terminating" judgements is particularly interesting. It is a distinction meant to differentiate the present meaning from the possible meaning of linguistic expressions, and thus to reassessing critically the dichotomies of factual judgement and value judgement, of descriptive and normative supported by the neo-positivists, especially by Carnap in Philosophy and Logical Syntax and by Schlick in Problems of Ethics. In a nutshell, Lewis's thesis is that value judgements operate in the entire area of normativity, including the logical determinations of coherence and cogency, as well as definitions of truth. Certainly, moral judgements or assertions on the 'good' must not be confused with those regarding what is normatively 'right' or valid in the scientific field. But this does not authorize us to use moral assertions as purely emotional expressions. It is thus easy to guess why Lewis never matched the neo-positivist approach to the question of the relationship between factual judgement and value judgement:

The validity of cognition itself is inseparable from that final test of it which consists in some valuable result of the action which it serves to guide. Knowledge - so the pragmatist conceives - is for the sake of action; and action is directed to realization of what is valuable. If there should be no valid judgments of value, then action would be pointless or merely capricious, and cognition would be altogether lacking in significance. (Lewis 1926: 112)

One can also trace the distinction between linguistic meaning and "sense meaning" back to the debate with Carnap, through which Lewis confirmed his reluctance to embark upon the path of conventionalism opened up by some promoters of the 'linguistic turn.' According to Murphey, the concept of 'sense meaning' has the advantage of offering a justification for the connection of conceptual schemes with the experience of the senses. ${ }^{14}$ It is just at that level that a comparison with Bourdieu's notion of 'perceptions' schemata' seems interesting. In fact, in both cases what is at the stake is the necessity of mediating between sensorial experience and the conceptual level.

\section{Analytic Truths and "Sense Meaning": Epistemic Tensions and Potentialities}

Summarizing drastically Lewis's position is a question of opposing the idea that analytic truths establish relationships only among linguistic terms. Rather, as he restates, analytic truths also involve the 'sense meaning,' that is to say, some reference to the concreteness of empirical facts, just because this allows us to safeguard the objective nature of the relationships between concepts and reality we normally assume in our ordinary course of cognitive activity. However, this does not imply any devaluation of the function of language's conventional aspect within scientific practices, nor, more generally, does it mean underestimating the linguistic nature of thought. Rather, Lewis's purpose was to guarantee the epistemological function of the intensional component of language. In this 
regard, it is useful to recall the four different ways of meaning presented in his 1946 work:

1. The denotation of a term is the class of all actual things to which the term applies.

2. The comprehension of a term is the classification of all possible or consistently thinkable things to which the term would be correctly applicable.

3. The signification of a term is that property in things the presence of which indicates that the term correctly applies; and the absence of which indicates that it does not apply.

4. Formally considered, the intension of a term is to be identified with the conjunction of all other terms each of which must be applicable to anything to which the given term would be correctly applicable (Lewis 1946: 39).

There is certainly a remarkable difference between the first three forms of meaning and the fourth, which simply corresponds to 'sense meaning.' It is a difference the importance of which is essential from an epistemological point of view, since it consists precisely in the primacy assigned to the 'sense meaning' regarding the verification of cognitive propositions. In fact, one must necessarily make reference to the intension of a term when the test of verification of cognitive assertions implies a test of significance/ denotation or when the empirical difference is called for showing meaning's differences; In addition, the intensional aspect of linguistic terms is basic with respect to operational meaning, which constitutes a standard for the precision and acceptability of concepts. It is not by chance that Lewis refers to Kant, asserting that "a sense meaning, when precise and explicit, is a schema; a rule or prescribed routine and an imagined result of it which will determine applicability of the expression in question" (Lewis 1946: 134-7). But, of course, every schema, as such, is flexible, namely changeable according to experience data.

The flexibility of 'sense meaning' schemas is nothing but a corollary of the constructive 'stuff' that characterizes any concept. In fact, the proper function of concepts is to arrange for the classification and discrimination of experience data, namely to organize their "buzzing blooming confusion" according to a certain operational meaning (Lewis 1926: 250), which, in turn, consists of a set of regularities that allows us to draw our attention to certain aspects of experience and to guide our behaviour. In other words, concepts are mental habits, to use Peirce's vocabulary, or dispositions to understand any sort of experience, logical or empirical. and, most importantly, to anticipate the possible results (or 'conceivable consequences,' in Peirce's terms) of a certain cognitive approach to our physical and cultural world. In so far as the anticipatory function of a concept can be more or less successfully satisfied by concrete actions and practices, concepts can be corroborated, amended, or even rejected. Thus Lewis reiterates the typically pragmatist intertwining of concepts, behavioural habits, and norms, insisting upon their reciprocal dynamic essence which ultimately appears strictly connected to the dynamic essence of both human experience and rational activity, in short, to the auto-corrective power of human intelligence that Peirce strictly connected to the 'teaching power' of experience.

Lewis's conception of 'sense meaning' has been variously criticized. One of the most wellknown comments was that of A.J. Ayer, who emphasized the difficulties of applying 'sense meaning' to abstract entities (photons, for example) or to sensible qualities (bitterness), and also to moral terms. But one could object that Ayer did not do justice to Lewis, because the concept of the 'image' upon which Lewis's theory of 'sense meaning' is based is strictly tied to the criteria of action, so that what is imagined is in reality a series of possible actions. Moreover, it is opportune to note that 'sense meaning' corresponds in 
part to the ineffable element of sensory experience mentioned earlier, namely to Lewis's assertion that there is something pre-linguistic and yet necessary for knowledge, something that we try to describe by means of language, granting the impossibility of translating it into conclusive words. According to 'conceptual pragmatism,' this does not mean supporting solipsism, but rather asserting the 'social construction' of reality and, at the same time, refusing the traditional causal theory of perception in the name of a pragmatic, interactive theory of knowledge and language. Last but not least, Lewis's epistemology makes room for an interesting approach to the problem of the relationship between human social habits and individual experience. Indeed, one could say that it is just the ineffable element of sensory experience, the actual effective source of the pragmatic a priori. Since humans cannot properly share their own immediate experiences through language, concepts are necessary in order to comprehend whether the meaning of my personal experience is similar or dissimilar to the experience of the same thing or fact that another person has. Accordingly, concepts helps us to understand the extent to which any possible difference on that level affects the way each person accepts, practices, and 'feels' social habits. Again, what is critical in such a process of understanding is human behaviour. Concepts are in themselves guides for human conduct, that is, they are signs of potential future actions. However, we can understand another person's mental store only by observing their practical and linguistic behaviour, the way in which their mental sets are implemented, experienced, and finally confronted with those of others. Such a systematic commitment may cast light upon habits and 'social schematism' - after Bourdieu, not necessarily in order to support the importance of social conventions or political agreements, but to value differences as productive rather than destructive of human potential. This is probably one of the very points of necessary connection between research in philosophy or the social sciences, providing that in any pragmatist account of human reality, 'mental' and 'behavioural' as well as 'social' and 'individual' are dynamically interconnected.

\section{BIBLIOGRAPHY}

AIKIN S. F., (2009), "Pragmatism, Experience, and the Given," Human Affairs 19, 19-27.

BARKER S. F., (2006), “Lewis on Implication,” Transaction of the Charles S. Peirce Society 42 (1), 10-6.

CALCATERRA R., (2003), Pragmatismo: I valori dell'esperienza. Letture di Peirce, James e Mead, Roma,

Carocci.

CALCATERRA R., (2011), Idee concrete. percorsi nella filosofia di John Dewey, Genoa, Marietti.

CALCATERRA R., (2013a), “Un sano senso della realtà,” Spazio Filosofico 8, 329-38.

Calcaterra R., (2013b), “Logic, Semiotics, and Ontology. Peirce's amended Kantianism," in

R. Lanfredini, A. Peruzzi (eds.), A Plea for Balance in Philosophy. Essays in Honor of Paolo Parrini, Pisa, ETS, 411-22. 
Colella E. P., (1992), C. I. Lewis. History and the Social Theory of Conceptualistic Pragmatism. The Individual and the Good Social Order, New York, E. Mellen Press.

CORCORAN J., (2006), “C. I. Lewis. History and Philosophy of Logic," Transaction of the Charles S. Peirce Society, 42 (1), 1-9.

DAYTON E., (1995), “C. I. Lewis and the Given," Transaction of the Charles S. Peirce Society, 31 (2), 254-84.

FERRARI M., (1998), “Un'altra storia. Tendenze e prospettive della più recente storiografia sulle origini dell'empirismo logico," Filosofia analitica 1996-1998, edited by M. di Francesco, D. Marconi, P. Parrini, Milano, Guerini e associati, 17-33.

FREGA R., (2012), Practice, Judgment, and the Challenge of Moral and Political Disagreement: a Pragmatist Account, Lanham, Lexington.

FRIEDMAN M., (1999), Reconsidering Logical Positivism, Cambridge, Cambridge University Press.

GoWANS C. W., (1989), "Two Concepts of the Given in C. I. Lewis. Realism and Foundationalism," Journal of the History of Philosophy 27, 573-90.

HAACK S., (1996), "Reflections of a Critical Common-Sensist," Transactions of the Charles S. Peirce Society, 359-73.

HоoKway C., (2007), "Pragmatism and the Given: C. I. Lewis, Quine and Peirce," in C. Misak (ed.), The Oxford Handbook of American Philosophy, Oxford, Oxford University Press.

JÄRVILEHTo L., (2014), “Concepts and the Real in C. I. Lewis’ Epistemology,” in K. R. Westphal (ed.), Realism, Science, and Pragmatism, New York, Routledge, 243-50.

KARLSSON M. M., (1997), “A Philosopher in Ultima Thule,” Epistemologia 20, 211-30.

LEWIS C. I., (1913), “A New Algebra of Implication and Some Consequences," Journal of Philosophy 10.

LEWIS C. I., (1918), A Survey of Symbolical Logic, Berkeley, University of California Press.

LEWIS C. I., (1923), “A Pragmatic Conception of the A Priori,” in Lewis 1970.

LEWIS C. I., (1926), “The Pragmatic Element of Knowledge,” in Lewis 1970.

LEWIS C. I., MWO (1956 [1929]), Mind and the World Order: Outlines of a Theory of Knowledge, New York, Dover Publications.

LEWIS C. I., (1941), “Logical Positivism and Pragmatism,” in Lewis 1970.

LEWIS C. I., (1945), An Analysis of Knowledge and Valuation, Open Court, La Salle.

LEWIS C. I., (1955), The Ground and Nature of Validity, Columbia University Press, New York.

LEWIS C. I., (1957), Our Social Inheritance, Bloomington, Indiana University Press.

LEWIS C. I., (1966), “Autobiography,” in Schilpp 1966.

LEWIS C. I., (1969), Values and Imperatives: Studies in Ethics, ed. by John Lange, Stanford, Stanford University Press.

LEWIS C. I., (1970), Collected Papers of Clarence Irving Lewis, ed. by John D. Goheen and John L. Mothershead Jr., Stanford, Stanford University Press.

MADDALENA G., (2009), Metafisica per assurdo, Soveria Mannelli, Rubbettino. 
MOTHERSILL M., (1966), “Lewis and Moral Philosopher," in Schilpp 1966, 1-21.

MURPHeY M., (2005), C. I. Lewis. The Last Great Pragmatist, Pittsburgh, Suny Press.

o'SHEA J. R., (2007), Wilfrid Sellars: Naturalism with a Normative Turn, Cambridge, Polity Press.

PARRINI P., SALMON P. \& M. SALMON (eds.), (2003), Logical Empiricism. Historical and Contemporary Perspectives, Pittsburgh, University of Pittsburgh Press.

ROBIN S., (2006), "Lewis, Peirce, and the Complexity of Classical Pragmatism," Transactions of Charles S. Peirce Society, 42 (1), 45-53.

RoSEnTHAL S., (2002), “A Pragmatic Appropriation of Kant,” Transactions of Charles S. Peirce Society, 38 (1-2), 253-66.

ROSENTHAL S., (2007), C. I. Lewis in Focus. The Pulse of Pragmatism, Bloomington-Indianapolis, Indiana University Press,.

Russell B. \& A. N. WhiteHEAD, (1919), Principia Mathematica, 2 vols., Cambridge, Cambridge

University Press.

Schilpp P. (ed.), (1966), The Philosophy of C. I. Lewis, La Salle, The Open Court.

TUZET G., (2006), “Sul concetto di esperienza. Ambiguità e criteri di analisi,” B@belonline/print 2, 213-28.

WitTGENSTEIn L., OC, (1969), On Certainty, edited by G. E. M. Anscombe and G. H. von Wright, trans. G. E. M. Anscombe and Denis Paul, Oxford, Basil Blackwell.

ZACK N., (2006), “Murray Murphey's Work and C. I. Lewis' Epistemology. Problems with Realism and the Context of Logical Positivism," Transactions of Charles S. Peirce Society, 42 (1), 32-44.

\section{NOTES}

1. I tried to show the complexity of classical pragmatism's notion of experience in Calcaterra 2003 and Calcaterra 2011.

2. Lewis (1923: 231).

3. Haack 1996.

4. Lewis also recognized the influence of the naturalistic logic of John Dewey.

5. I sketched Peirce's critiques of Kant in Calcaterra 2013b.

6. Russell, Whitehead 1910.

7. See also (MWO: 19-25).

8. See (MWO: 237, 245).

9. On Lewis's commitment to realism, see Järvilehto 2014.

10. See (OC: §§ 94-105).

11. For a synthetic account of a possible integration of Wittgenstein's overcoming of the realismantirealism counterposition with Peirce's and James's approach to the notion of reality, see Calcaterra 2013a.

12. An analysis of these instances of ambivalence and their epistemological repercussions can be found in Gowans 1989.

13. A detailed explanation of this aspect can be found in Murphey (2005: chap. IV). See also O'Shea (2007: chap. 5).

14. Murphey (2005: $270 \mathrm{ff}$.$) .$ 


\section{ABSTRACTS}

This paper proposes the "conceptual pragmatism" of C. I. Lewis as a useful epistemological orientation for studying the relationship between the social and individual registers, in particular as it is set out in Bourdieu's sociology of practice. Bourdieu's concepts of habits based upon 'social schematism' and of culture as a 'second nature,' as well as Lewis' conception of logical schemas constructed by humans are all formulated in the wake of Kant, and mediating between sensorial experience and the conceptual level is a common issue for Lewis and the French sociologist. This paper discusses Lewis' controversial idea of "sense meaning" in order to show his commitment to a pragmatic, interactive theory of knowledge and language. Moreover, I emphasize Lewis' intertwining of conceptual schemas, actions, and reality as a theoretical network for reshaping analysis of the relationship between sociality and individuality according to a pragmatist perspective, and for implementing and improving Lewis' commitment to observing, describing, and interpreting the effective functioning of conceptual schemas, one that includes an option in favor of an externalist philosophical methodology which, in principle, tallies with the methodological attitude that mostly characterizes the contemporary social sciences.

\section{AUTHOR}

\section{ROSA M. CALCATERRA}

Università Roma Tre

rosamaria.calcaterra[at]uniroma3.it 